\title{
Elemental concentrations of ambient particles and cause specific mortality in Santiago, Chile: a time series study
}

Ana Valdés ${ }^{1,2^{*}}$, Antonella Zanobetti ${ }^{3}$, Jaana I Halonen ${ }^{3,5}$, Luis Cifuentes ${ }^{4}$, Diego Morata ${ }^{6}$ and Joel Schwartz ${ }^{3}$

\begin{abstract}
Background: The health effects of particulate air pollution are widely recognized and there is some evidence that the magnitude of these effects vary by particle component. We studied the effects of ambient fine particles (aerodynamic diameter $<2.5 \mu \mathrm{m}, \mathrm{PM}_{2.5}$ ) and their components on cause-specific mortality in Santiago, Chile, where particulate pollution is a major public health concern.

Methods: Air pollution was collected in a residential area in the center of Santiago. Daily mortality counts were obtained from the National Institute of Statistic. The associations between $\mathrm{PM}_{2.5}$ and cause-specific mortality were studied by time series analysis controlling for time trends, day of the week, temperature and relative humidity. We then included an interaction term between $\mathrm{PM}_{2.5}$ and the monthly averages of the mean ratios of individual elements to $\mathrm{PM}_{2.5}$ mass.

Results: We found significant effects of $\mathrm{PM}_{2.5}$ on all the causes analyzed, with a $1.33 \%$ increase (95\% Cl: 0.87-1.78) in cardiovascular mortality per $10 \mu \mathrm{g} / \mathrm{m}^{3}$ increase in the two days average of $\mathrm{PM}_{2.5}$. We found that zinc was associated with higher cardiovascular mortality. Particles with high content of chromium, copper and sulfur showed stronger associations with respiratory and COPD mortality, while high zinc and sodium content of $\mathrm{PM}_{2.5}$ amplified the association with cerebrovascular disease.

Conclusions: Our findings suggest that $\mathrm{PM}_{2.5}$ with high zinc, chromium, copper, sodium, and sulfur content have stronger associations with mortality than $\mathrm{PM}_{2.5}$ mass alone in Santiago, Chile. The sources of particles containing these elements need to be determined to better control their emissions.
\end{abstract}

Keywords: Air pollution, Mortality, $\mathrm{PM}_{2.5}$, Elements

\section{Background}

Particulate air pollution is a main environmental risk factor for human health, and short-term associations between mortality and particulate pollutants are well established [1-3]. Many studies have suggested that the magnitude of the association between mortality and particles differs by particle size, with fine particles (particles with aerodynamic diameter less than $\left.2.5 \mu \mathrm{m}, \mathrm{PM}_{2.5}\right)$ having greater effects than larger particles (diameter

\footnotetext{
* Correspondence: ana.valdes@sernageomin.cl

'Laboratoire de Géosciences Environnement Toulouse (GET), Observatoire Midi-Pyrénées, 14, Avenue Edouard, Belin, Toulouse 31400, France

${ }^{2}$ Departamento de Geología Aplicada, Servicio Nacional de Geología y Minería de Chile, Avenida Santa María 0104, Providencia 7520405, Santiago, Chile

Full list of author information is available at the end of the article
}

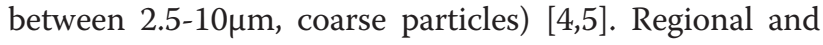
seasonal differences in the health effects of particles have also been reported [6-8]. Composition of particles also varies by season, suggesting this may play a role in the toxicity of particles. Due to the lack of data on particulate composition, the health effects of specific particulate components have not been widely studied, and most epidemiological studies performed on a population level are from the United States [9-12]. Studies that control for seasonal temperature as a surrogate for ventilation rate have identified sulfur, nickel, and vanadium as particularly toxic [9-11], while studies that ignored confounding by seasonal temperature have reported more mixed results $[13,14]$. By identifying the elements most toxic to human health, we can move to more efficient

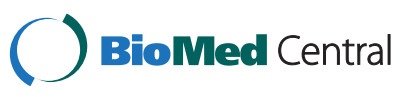


regulations for particulate matter. Therefore confirming these associations, particularly in other parts of the world, is important.

In Santiago, Chile, air pollution is a major public health concern because of its dense population and the geography of the area [15]. The city is located between the Andean Cordillera at the East, and Coastal Range at the West. In the Central Valley of Chile, during the majority of the year there is a thermal inversion layer. During autumn and winter, this layer is produced as a result of cooling of the ground. When these phenomena coexist, the conditions became favorable to accumulation of pollution, and the levels of particulate matter regularly exceed the daily standard by U.S. Environmental Protection Agency and World Health Organization (WHO) $[16,17]$. Previous studies have provided evidence that particulate pollution in Santiago increases the risk of mortality $[4,18,19]$ and morbidity $[20,21]$. The most recent studies were also able to differentiate the health effects of specific elemental components of particles $[18,22]$. Unfortunately, as in the U.S., $\mathrm{PM}_{2.5}$ mass components in Chile are not measured on a daily basis, hence the data are sparse, and time series analyses have weak statistical power.

We have previously introduced a methodology to take better advantage of sparse data, specifically when speciation data only exist every 3-6 days. $\mathrm{PM}_{2.5}$ is monitored more frequently, almost daily. The method was applied to U.S. mortality and morbidity data by Franklin et al. [9] and Zanobetti et al. [11]. In this method, the first stage was fitted on a daily time series analysis by season using daily $\mathrm{PM}_{2.5}$ data. In the second stage, we look at how the relative fraction of $\mathrm{PM}_{2.5}$, from different elements averaged by season, modifies the $\mathrm{PM}_{2.5}$ association. This same approach was subsequently adopted by Bell et al. [10]. In this study we have chosen a similar approach where we let the $\mathrm{PM}_{2.5}$ coefficients vary by month, and used the monthly ratios of components to total mass to explain the variations in those coefficients.

We applied this approach to cause-specific mortality during the years 1998-2007. We extracted several different elements of fine particles (aluminium (Al), sodium $(\mathrm{Na})$, silicon $(\mathrm{Si})$, sulfur $(\mathrm{S})$, chloride $(\mathrm{Cl})$, calcium $(\mathrm{Ca})$, chromium $(\mathrm{Cr})$, manganese $(\mathrm{Mn})$, nickel $(\mathrm{Ni})$, potassium $(\mathrm{K})$, iron $(\mathrm{Fe})$, copper $(\mathrm{Cu})$, zinc $(\mathrm{Zn})$, selenium $(\mathrm{Se})$, bromine $(\mathrm{Br})$, lead $(\mathrm{Pb}))$, and studied the associations with mortality for all cardiovascular (CVD), all respiratory, cerebrovascular, and chronic obstructive pulmonary disease (COPD).

\section{Methods}

\section{Air pollution and meteorological data}

The $\mathrm{PM}_{2.5}$ mass and elements concentration data were obtained from Parque O'Higgins (P.O), as in prior studies
$[18,22,23]$, one of the seven air quality monitoring stations of the Automatic Monitory of Atmospheric Contaminants Network (MACAM NETWORK). This station is located in a residential area in one of the main green areas in the center of Santiago. East of the station is the Principal National Route "Carretera Panamericana" and to the west is the University of Chile Campus. Additionally, in three of the stations temperature, humidity, solar irradiation and wind direction are measured [24].

Particulate matter was collected on $37 \mathrm{~mm}$ diameter Teflon filters (Pall Flex) [24] by a gravimetric method using a Dichotomous sampler (Sierra Andersen 244, Smyrna, GA). This method allows the collection of particle sizes smaller than $2.5 \mu \mathrm{m}$ (fine fraction), and in the range of $2.5-10 \mu \mathrm{m}$ (coarse fraction) with a bulk flow rate of $16-181 \mathrm{~min}^{-1}$. This semiautomatic equipment is programmable for sampling periods of 24 hours, and it allows the simultaneous collection of the two particulate fractions. The samples were collected from 10:00 a.m. to 10:00 a.m. the next day in autumn and winter, and from midnight to midnight in spring and summer. The measurements were performed daily from April to September, every two days in October, November and March, and every three days in December, January and February from 1998 to 2007. The frequency of monitoring is based on the levels of pollution observed during the year and decided by the National Environment Commission. Therefore, daily monitoring in the cold months (April to September) is consistent with higher levels of pollution. Lower pollutant concentrations have been observed in the warm season due to better ventilation conditions and therefore less frequent sampling was performed.

The physical conditioning of the filters was performed in the gravimetric laboratory at the Department of Public Health of the Ministry of Health. Filters were weighted before and after use on an electronic microbalance, Precisa (Swiss) 40SM-200A, allowing $1 \mu$ g error, and stored in individual plastic boxes in dry chambers. The laboratory atmosphere had a $50 \%$ controlled relative humidity and temperature between $20^{\circ} \mathrm{C}$ and $25^{\circ} \mathrm{C}$. The elemental analyses for the $\mathrm{PM}_{2.5}$ filters were conducted using X-ray fluorescence at the Desert Research Institute. Six to eight filters per month were analyzed for elements, and approximately $10 \%$ of the samples were blank. The limit of detection (LOD) was calculated for each element as three times the standard error of the blanks. Only elements that had at least $95 \%$ of all reported values above LOD were included in the statistical analysis, as previously described [18,23].

Based on the results from previous epidemiological studies $[18,25]$ we focused on the species with different sources and toxicological background. We examined the following species: aluminium ( $\mathrm{Al}$ ), sodium $(\mathrm{Na})$, silicon $(\mathrm{Si})$, sulfur $(\mathrm{S})$, chloride $(\mathrm{Cl})$, calcium $(\mathrm{Ca})$, chromium 
$(\mathrm{Cr})$, manganese $(\mathrm{Mn})$, nickel $(\mathrm{Ni})$, potassium $(\mathrm{K})$, iron $(\mathrm{Fe})$, copper $(\mathrm{Cu})$, zinc $(\mathrm{Zn})$, selenium $(\mathrm{Se})$, bromine $(\mathrm{Br})$, and lead $(\mathrm{Pb})$.

\section{Health data}

Death certificate data in Santiago, with a population around of 6 million inhabitants, was obtained from the National Statistic Institute for the years 1998 to 2007. The causes were classified according to the International Classification of Disease, $9^{\text {th }}$ Revision (ICD-9). We examined daily mortality counts of respiratory diseases (ICD-9: 460-519), cardiovascular diseases (CVD, ICD-9: 390-429), chronic obstructive pulmonary diseases (COPD, ICD-9: 490-496) and cerebrovascular diseases (cerebro, ICD-9: 430-459).

\section{Statistical methods}

We applied a time series analysis using Poisson regression in a generalized additive model to examine the association between daily counts of cause-specific mortality and daily $\mathrm{PM}_{2.5}$ mass concentrations. This model adjusts for the over-dispersion of the Poisson-distributed data. The model controlled for seasonality and long term trend with a penalized spline with 5 degrees of freedom (df) for each year; day of the week using indicator variables; the two days average temperature and relative humidity with a penalized spline with $3 \mathrm{df}$. Because particle species were not measured every day, we computed the mean monthly ratios of the elemental concentrations to the total $\mathrm{PM}_{2.5}$ mass for each month therefore eliminating the missing data issue. We first fit a time series analysis of daily $\mathrm{PM}_{2.5}$ and daily counts of cause-specific mortality. We then included in the models, one at the time, the interaction terms between the moving average of lag days 0 and 1 of $\mathrm{PM}_{2.5}$ and the mean monthly ratio of each individual element to $\mathrm{PM}_{2.5}$ mass, the model is:

$$
\begin{aligned}
\log \left[\mathrm{E}\left(\mathrm{Y}_{\mathrm{t}}\right)\right]= & \beta_{0}+f\left(\text { season } / \text { time }_{\mathrm{t}}\right)+f\left(\text { temp }_{\mathrm{t}}\right) \\
& +f\left(\text { relhum }_{\mathrm{t}}\right)+\beta_{1} \beta_{6} \text { weekday }_{6}+\beta_{7} \mathrm{PM}_{2.5} \\
& +\beta_{8}{\text { monthly element concentration } / \mathrm{PM}_{2.5}} \\
& +\beta_{9} \mathrm{PM}_{2.5} \\
& * \text { monthly element concentration } / \mathrm{PM}_{2.5}
\end{aligned}
$$

where, $E(Y t)$ is the expected value of the daily count of mortality $\mathrm{Yt}, \mathrm{f}$ are the penalized splines of seasonality and long-term trend and weather, $\beta_{1}-\beta_{6}$ are the coefficients for the weekdays, $\beta_{7}$ and $\beta_{8}$ are respectively the main effects of $\mathrm{PM}_{2.5}$ and the monthly averages of the element concentrations/ $\mathrm{PM}_{2.5}$ and $\beta_{9}$ is the interaction term. This allowed us to see whether the PM coefficient was systematically higher or lower when more (or less) of the PM mass consisted of a particular element.

As those > 65 years of age have been found more susceptible for the effects of air pollution [26], analyses were run separately for this age group. As sensitivity analyses, we ran the models using different degrees of freedom for season, and different lags for the meteorological variables.

The effect estimates are expressed as a percent increase in mortality per $10 \mu \mathrm{g} / \mathrm{m}^{3}$ increase in the two-day average $\mathrm{PM}_{2.5}$ mass concentration. Because the interaction was determined between two continuous variables we computed the percent increase in cause-specific mortality per $10 \mu \mathrm{g} / \mathrm{m}^{3}$ increase in the two-day average $\mathrm{PM}_{2.5}$ and for an interquartile (IQR) increase in each monthly average of the element concentrations $/ \mathrm{PM}_{2.5}$. We used SAS 9.1 [27] for data management, and R 2.7.2 [28] for regression modeling.

\section{Results}

In Santiago, Chile, there were 68,374 deaths from cardiovascular diseases, 24,517 from respiratory diseases, 7,702 from COPD and 22,698 from cerebrovascular diseases over the years 1998 to 2007. Table 1 shows the distribution of the mortality by cause, together with the distribution of the weather variables and $\mathrm{PM}_{2.5}$ that had a median 24 hour concentration of $34 \mu \mathrm{g} / \mathrm{m}^{3}$. The distributions of the concentration ratios of elements to the total $\mathrm{PM}_{2.5}$ mass are presented in Table 2. The largest variations observed in this table $(\mathrm{Al}, \mathrm{Na}, \mathrm{Ca}, \mathrm{Cl}, \mathrm{Fe}, \mathrm{K}, \mathrm{S}$ and $\mathrm{Si}$ ) are associated to elements of natural origin with exception of $\mathrm{S}$, that is probably related to emissions from a large copper smelter in the area [29]. The lower values observed in the rest of the elements probably represent elements of an anthropogenic origin. Table 2 shows also the interquartile range (IQR) of the monthly averages that have been used to compute the percent increase for each element.

The associations between cause-specific mortality and $\mathrm{PM}_{2.5}$ were significant for all of the causes analyzed. The strongest effects were observed for the two-day average

Table 1 Distribution of daily mortality by cause, weather and $\mathrm{PM}_{2.5}$ in Santiago, Chile in 1998-2007

\begin{tabular}{lllllll}
\hline & $\mathbf{5 \%}$ & $\mathbf{2 5 \%}$ & $\mathbf{5 0 \%}$ & $\mathbf{7 5 \%}$ & $\mathbf{9 5 \%}$ & $\mathbf{N}$ \\
\hline Cause of death & & & & & & \\
\hline Cardiovascular & 11 & 15 & 19 & 23 & 29 & 3562 \\
\hline Cerebrovascular & 2 & 4 & 6 & 8 & 11 & 3562 \\
\hline All respiratory & 2 & 4 & 6 & 9 & 15 & 3562 \\
\hline COPD & 0 & 1 & 2 & 3 & 5 & 3562 \\
\hline Environmental variable & & & & & & \\
\hline PM $_{2.5} \mu \mathrm{g} / \mathrm{m}^{3}$ & 11 & 20 & 34 & 61 & 104 & 2435 \\
\hline PM $_{2.5} 2$ days average, $\mu \mathrm{g} / \mathrm{m}^{3}$ & 11 & 18 & 28 & 53 & 96 & 3204 \\
\hline Temperature $^{\circ} \mathrm{C}$ & 8 & 13 & 17 & 21 & 26 & 3562 \\
\hline Relative humidity $\%$ & 34 & 50 & 63 & 75 & 88 & 3562 \\
\hline
\end{tabular}


Table 2 Distribution of the element-to- $\mathrm{PM}_{2.5}$ mass proportions and interquartile range (IQR) of the monthly averages of these ratios

\begin{tabular}{llllllll}
\hline Element $\left.\mathbf{( n g} / \mathbf{m}^{\mathbf{3}}\right)$ & $\mathbf{5 \%}$ & $\mathbf{2 5 \%}$ & $\mathbf{5 0}$ & $\mathbf{7 5 \%}$ & $\mathbf{9 5 \%}$ & $\mathbf{N}$ & IQR of $\mathbf{m o n t h l y ~ r a t i o s}$ \\
\hline $\mathrm{Al}$ & 0.55 & 1.64 & 3.26 & 6.68 & 12.71 & 816 & 4.94 \\
\hline $\mathrm{Na}$ & 0.47 & 2.36 & 6.29 & 14.21 & 27.71 & 797 & 11.42 \\
\hline $\mathrm{Br}$ & 0.09 & 0.19 & 0.31 & 0.62 & 2.33 & 814 & 0.39 \\
\hline $\mathrm{Ca}$ & 1.02 & 2.38 & 4.00 & 5.89 & 9.50 & 816 & 3.36 \\
\hline $\mathrm{Cl}$ & 0.16 & 0.80 & 2.20 & 5.16 & 15.87 & 720 & 4.64 \\
\hline $\mathrm{Cr}$ & 0.03 & 0.06 & 0.10 & 0.14 & 0.26 & 800 & 0.04 \\
\hline $\mathrm{Cu}$ & 0.26 & 0.54 & 0.75 & 1.08 & 1.94 & 815 & 0.36 \\
\hline $\mathrm{Fe}$ & 2.92 & 6.37 & 9.07 & 12.41 & 18.70 & 816 & 5.23 \\
\hline $\mathrm{K}$ & 3.58 & 5.97 & 8.30 & 12.02 & 23.43 & 816 & 7.23 \\
\hline $\mathrm{Mn}$ & 0.13 & 0.29 & 0.46 & 0.65 & 1.04 & 816 & 0.21 \\
\hline $\mathrm{Ni}$ & 0.01 & 0.02 & 0.03 & 0.05 & 0.09 & 751 & 0.02 \\
\hline $\mathrm{Pb}$ & 0.31 & 0.64 & 0.99 & 2.63 & 8.24 & 815 & 2.74 \\
\hline $\mathrm{Se}$ & 0.01 & 0.04 & 0.08 & 0.15 & 0.33 & 755 & 0.10 \\
\hline $\mathrm{Si}$ & 1.91 & 4.44 & 8.56 & 16.42 & 28.68 & 816 & 13.47 \\
\hline $\mathrm{S}$ & 9.59 & 22.79 & 36.72 & 52.13 & 81.10 & 816 & 22.33 \\
\hline $\mathrm{Zn}$ & 0.79 & 1.39 & 2.05 & 2.88 & 4.96 & 816 & 0.93
\end{tabular}

and all respiratory mortality with a $1.75 \%$ increase $(95 \%$ CI: $1.01-2.49)$, and for COPD mortality with $1.94 \%$ increase (95\% CI: $0.63-3.27$ ) per $10 \mu \mathrm{g} / \mathrm{m}^{3}$ increase in $\mathrm{PM}_{2.5}$ (Table 3). We also found significant association for cardiovascular and cerebrovascular mortality (Table 3).

Table 3 Percent increase (95\% Confidence interval) in cause-specific mortality per $10 \mu \mathrm{g} / \mathrm{m}^{3}$ increase in the same day and 2-day average $\mathbf{P M}_{2.5}$

\begin{tabular}{|c|c|c|c|c|}
\hline Cause of death & Lag & $\%$ & $95 \% \mathrm{Cl}$ & \\
\hline \multicolumn{5}{|l|}{ All } \\
\hline \multirow[t]{2}{*}{ Cardiovascular } & Same day & 0.71 & 0.30 & 1.13 \\
\hline & 2 days average & 1.33 & 0.87 & 1.78 \\
\hline \multirow[t]{2}{*}{ Cerebrovascular } & same day & 0.49 & -0.22 & 1.21 \\
\hline & 2 days average & 1.13 & 0.36 & 1.90 \\
\hline \multirow[t]{2}{*}{ All respiratory } & same day & 0.24 & -0.42 & 0.90 \\
\hline & 2 days average & 1.75 & 1.01 & 2.49 \\
\hline \multirow[t]{2}{*}{ COPD } & same day & 0.36 & -0.83 & 1.57 \\
\hline & 2 days average & 1.94 & 0.63 & 3.27 \\
\hline \multicolumn{5}{|c|}{ Over 65 years of age } \\
\hline \multirow[t]{2}{*}{ Cardiovascular } & same day & 0.77 & 0.32 & 1.23 \\
\hline & 2 days average & 1.54 & 1.05 & 2.04 \\
\hline \multirow[t]{2}{*}{ Cerebrovascular } & same day & 0.51 & -0.28 & 1.31 \\
\hline & 2 days average & 1.29 & 0.44 & 2.15 \\
\hline \multirow[t]{2}{*}{ All respiratory } & same day & 0.41 & -0.30 & 1.13 \\
\hline & 2 days average & 2.13 & 1.34 & 2.93 \\
\hline \multirow[t]{2}{*}{ COPD } & same day & 0.35 & -0.94 & 1.65 \\
\hline & 2 days average & 1.95 & 0.54 & 3.38 \\
\hline
\end{tabular}

Results for all ages and for age over 65 years.
When $\mathrm{PM}_{2.5}$ concentrations were restricted to $<100 \mu \mathrm{g} / \mathrm{m}^{3}$ the results didn't change much, only a slight increase in the effects was observed (data not shown). The effect estimates were slightly greater for those over 65 years of age compared to the whole sample. Again the strongest associations were observed for all respiratory and COPD mortality (Table 3).

Figure 1 shows for each cause of death the results for the two-day average of $\mathrm{PM}_{2.5}$ together with the effects of the elements. When we included the interaction term for $\mathrm{PM}_{2.5}$ and the elements, we found that a $10 \mu \mathrm{g} / \mathrm{m}^{3}$ increase in the two-day average $\mathrm{PM}_{2.5}$ and an IQR increase in monthly average of zinc concentration/ $/ \mathrm{PM}_{2.5}$ increased the most the effect of $\mathrm{PM}_{2.5}$ on cardiovascular (1.87\%; 95\% CI: 1.04-2.71) and cerebrovascular (2.37\%; 95\% CI: 0.93-3.83) mortality. Increase in sodium was also associated with cerebrovascular mortality (3.11\%, 95\% CI: 1.51-4.72).

Chromium and sulfur modified the association between $\mathrm{PM}_{2.5}$ and death from all respiratory diseases. A $10 \mu \mathrm{g} / \mathrm{m}^{3}$ increase in the two-day average of $\mathrm{PM}_{2.5}$ and an IQR increase in monthly average of chromium concentration $/ \mathrm{PM}_{2.5}$ was associated with increases of $3.35 \%$ (95\% CI: 1.90-4.83) in all respiratory mortality.

Other elements also had significant associations with all of the outcomes (Figure 1 and Additional file 1 Table S1).

Results of the sensitivity analyses had minor effect on the results (data not shown).

\section{Discussion}

In Santiago, Chile, we found that $\mathrm{PM}_{2.5}$ was associated with cause-specific mortality. The effect size per $10 \mu \mathrm{g} / \mathrm{m}^{3}$ 


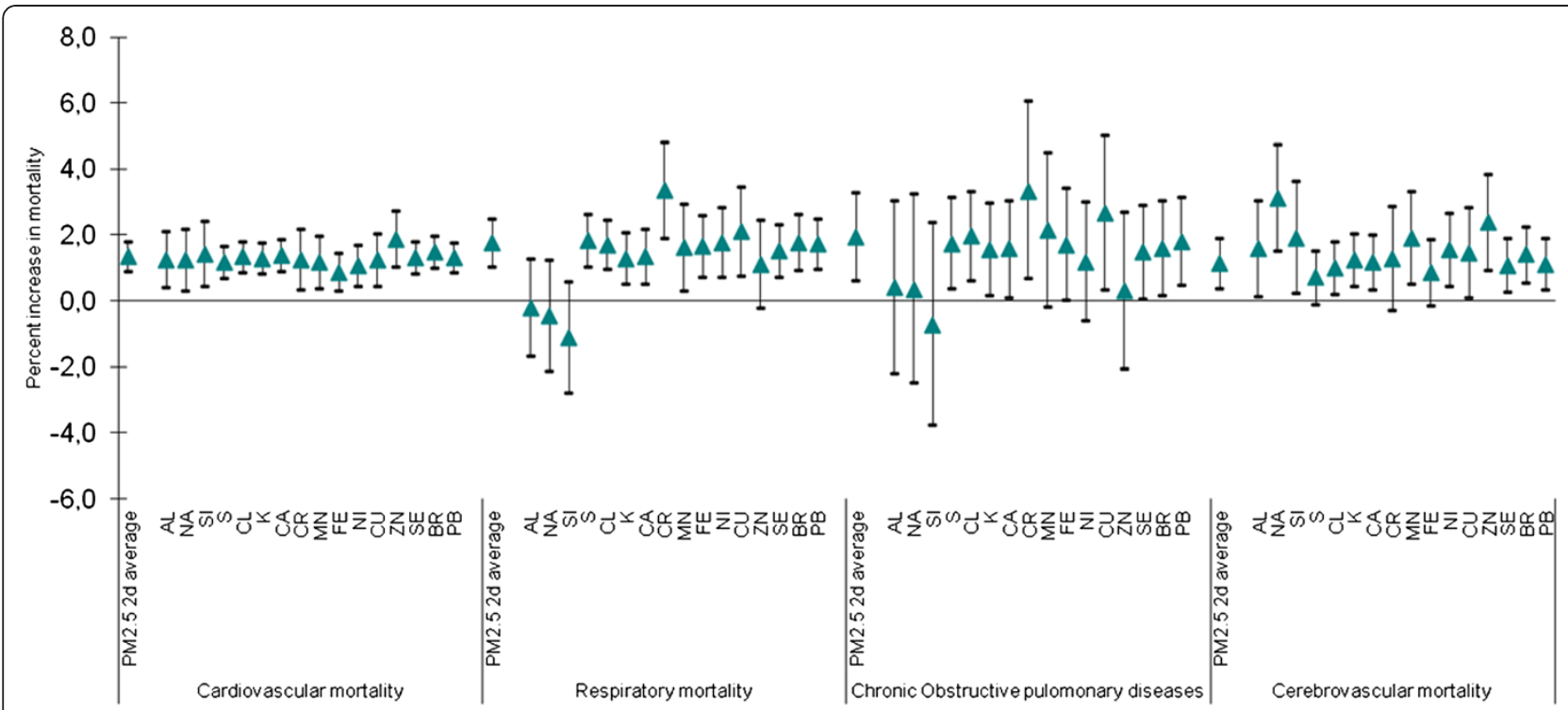

Figure 1 Percent increase $\left(95 \%\right.$ Confidence Interval) in cause-specific mortality per $10 \mu \mathrm{g} / \mathrm{m}^{3}$ increases in the 2 days average $P M_{2.5}$, and for an IQR increase in the elements after including the interaction between $\mathrm{PM}_{2.5}$ and the mean monthly concentration ratios of elements in the total $\mathrm{PM}_{2.5}$ mass.

of $\mathrm{PM}_{2.5}$ is similar, but higher to that reported by Zanobetti and Schwartz in an analysis of over 100 U.S. cities [30]. This confirms those associations may be applicable elsewhere. In examining the composition of fine particles, we found that zinc $(\mathrm{Zn})$ was specifically associated with cardiovascular and cerebrovascular deaths, while chromium $(\mathrm{Cr})$ had the strongest associations with respiratory mortality.

The associations we found between $\mathrm{PM}_{2.5}$ and causespecific mortality were consistent with previous studies done in Chile $[19,20,31]$ and in the U.S. [30]. In regard to the elemental concentrations of fine particles, we found a clear relation for all respiratory mortality with $\mathrm{Cr}$; while $\mathrm{Zn}$ was associated with higher than average toxicity for both cardiovascular and cerebrovascular deaths. Increased cardiovascular mortality has previously been linked to increases in the levels of elemental and organic carbon, nitrates, sulfates, potassium, copper and iron in California [32]. In line with our findings, an earlier Canadian study has also reported associations between total mortality and zinc [33]. Due to the fact that the PM components have been available only for one day in three or six, some studies in the U.S. have used a method similar to the one presented in this study, and showed that PM chemical components modify the PM effect to mortality $[9,12]$ or hospitalization $[10,11]$. Among these studies, the elements that have most often been found to increase the health risk are nickel, vanadium, aluminum, arsenic, sulfate, bromine, and silicon.

The effects of particulate species on total mortality in Chile have been studied by Cakmak et al. [18]. They also found associations between mortality and organic carbon (RR 1.07; 95\% CI: 1.06-1.07), Cu (RR 1.06; 95\% CI: 1.05-1.08) and Fe (RR 1.05; 95\% CI: 1.04-1.06), but they only had 655 observations over the nine years of study. Cakmak and co-authors [18] found also that soil-related particles included elements $\mathrm{Al}, \mathrm{Ca}, \mathrm{Fe}$, and $\mathrm{Si}$, and that these particles had weaker but statistically significant mortality effect.

In an earlier study on the effects of particulate components and sources on emergency department visit counts in Chile, particles related to combustion sources included elements such as $\mathrm{Cr}, \mathrm{Cu}, \mathrm{Fe}, \mathrm{Mn}$ and $\mathrm{Zn}$, and they were associated with total and respiratory emergency visits [22]. The association between respiratory morbidity and a factor containing $\mathrm{Zn}$ is consistent with the current results; however we found no clear associations between mortality and other soil-related particulate elements $\mathrm{Al}, \mathrm{Ca}$, or $\mathrm{Fe}$, which may have been related to the large variation in the levels of these elements. The reasons for different associations between different elements and certain causes of death are to be determined. Ambient concentrations and bio-accessibility may affect the toxicity degree, for example $\mathrm{Zn}, \mathrm{Mn}$, and $\mathrm{Cu}$ present higher respiratory uptakes than $\mathrm{Cd}$ and $\mathrm{Pb}$ [34].

The identification of the emission sources of these metals is one of the central problems to discuss. In the current study, sulfur $(S)$ was associated with higher respiratory mortality than the total $\mathrm{PM}_{2.5}$ mass, and in a previous study, sulfur has been related with the emissions from a smelter [35]. In fact, one of the potential sources in Santiago is the large copper smelter Caletones 
that emits oxidized sulfur in the Santiago basin and produces sulfur rich fine particles [29]. Zn has been categorized as a combustion related element along with $\mathrm{Cr}, \mathrm{Cu}$, $\mathrm{Fe}$ and $\mathrm{Mn}$ [18]. The harmful particle sources identified by Cakmak et al. [18] are consistent with the ones previously recognized by Artaxo et al. [36]. They found that the principal source of $\mathrm{Zn}$ is oil combustion in particular, while Hedberg et al. [35] and Kavouras et al. [37] related $\mathrm{Zn}$ as well as $\mathrm{Cu}$ with the copper smelters. Usually, many elements appear to be related to more than one source. For example Fe can be provided by two potential sources: copper smelting processes and/or natural lithogenic source, as suggested by Morata et al. [38]. As already said, $\mathrm{Zn}$ also shows this behavior as it appears related to copper smelting and oil/coal combustion. Finally, the presence of $\mathrm{Na}$ in Santiago is related to convective process from marine source.

The contradictory results are possibly related to local differences in particulate sources. This underlines the importance of determining the health effects of particulate matter at various locations by elemental components. In Chile there is an ongoing work related with the characterization and identification of particulate sources; however, there are not many studies that show the relationship between public health problems and specimen elements and their sources of emission. As a future prospect, the use of isotopes can help tracing the sources in urban air pollution. This would allow distinguishing different sources associated with specific elements such as $\mathrm{Mn}, \mathrm{Fe}, \mathrm{Zn}, \mathrm{S}$ and to discriminate between local sources from the regional, like copper smelters.

There are some limitations to this study. One is that the data collection for the particulate matter was not uniform throughout the year, and daily data was available only for the cold months from April to September. Averaging the elemental concentrations over a month reduced the missing data (measurements daily in winter, every three days in the summer), but may have reduced the variation in the element concentrations, which may have attenuated the strength of the observed associations. However, this would affect the used data equally since the elemental concentrations were similarly assessed in for each month. The air pollution data, was also collected at one measurement location, which may cause some exposure to misclassification. Having data from only one measurement station may lead to Berkson error, which reduces the power to reveal significant effects [39].

Finally, we tested several elemental fractions and outcomes, and thus, the possibility of chance findings due to multiple testing should be considered. However, if one in 20 tests at $95 \%$ confidence level are expected to be significant due to chance, [40] our 18 significant findings out of 64 tests (16 elements * 4 outcomes) far exceeds this. The relative strength of the association with the elements needs to be taken with caution and more studies are needed to confirm our findings.

\section{Conclusions}

It seems that $\mathrm{PM}_{2.5}$ mass alone is not a sufficient metric when evaluating the health effects of PM exposure. Our findings suggest that particles with high zinc, chromium, copper, sodium, and sulfur content may be related to greater health effects than those observed for the conventionally used measure of total $\mathrm{PM}_{2.5}$ mass, in Santiago, Chile. The sources of particles formed of these elements need to be determined in order to better control the emissions of these harmful particulates.

\section{Additional file}

Additional file 1: Table S1. Percent increase (95\% Confidence Interval) in cause-specific mortality per $10 \mu \mathrm{g} / \mathrm{m}^{3}$ increase in the 2 days average $\mathrm{PM}_{2.5}$, and for $10 \mu \mathrm{g} / \mathrm{m}^{3}$ increases in 2 days average $\mathrm{PM}_{2.5}$ and an IQR increase in the elements after including the interaction between $\mathrm{PM}_{2.5}$ and the mean monthly concentration ratios of elements in the total $\mathrm{PM}_{2.5}$ mass. $(\mathrm{N}=3113)$

\section{Abbreviations}

$\mathrm{PM}_{25}$ : Particulate Matter with aerodynamic diameter < 2.5um; Al: Aluminium; Na: Sodium; Si: Silicon; S: Sulphur; Cl: Chloride; Ca: Calcium; Cr: Chromium; Mn: Manganese Ni: nickel; K: Potassium; Fe: Iron; Cu: Copper; Zn: Zinc; Se: Selenium; Br: Bromine; Pb: Lead; CVD: Cardiovascular; COPD: Chronic obstructive pulmonary disease; P.O: Parque O'Higgins; MACAM

NETWORK: Automatic Monitory of Atmospheric Contaminants Network; LOD: The limit of detection; ICD-9: International Classification of Disease $9^{\text {th }}$ Revision; $E\left(Y_{t}\right)$ : Value of the daily count of mortality; $Y_{t}, f$ : Penalized splines of seasonality and long-term trend and weather; $\beta_{1}-\beta_{6}$ : Coefficients for the weekdays; $\beta_{7}$ and $\beta_{8}$ : Main effects of $\mathrm{PM}_{2.5}$ and the monthly averages of the element concentrations/PM2.5; $\beta_{9}$ : The interaction term.

\section{Competing interests}

The authors state that there are no previous publications from the same study in printed or electronic form, and that the paper is not being considered in publication elsewhere. Authors declare no competing interests. The study was not funded or sponsored by industry, or written by a professional medical writer.

\section{Author's contributions}

AV participated to the planning of the study, carried out the chemical analyses, and drafted the manuscript, AZ participated to the planning of the study, analyzed the data, and helped drafting the article, J॥H participated to interpretation of data and drafting of the manuscript, LC helped with the acquisition of the data and critically reviewed the manuscript, DM participated to the planning of the study, helped with the acquisition of the data and critically reviewed the manuscript, JS participated to the planning of the study and interpretation of data and critically reviewed the manuscript. All authors have approved the final version of the manuscript.

\section{Acknowledgements}

This study was supported by ALBAN scholarship program, CNRS-IRD and GET, Université Paul Sabatier, Toulouse, France, EPA grant R R832416 and National Institute of Statistic, Chile. The authors thank Pedro Oyola from Mario Molina Institute and Petros Koutrakis from Department of Environmental Health, Harvard School of Public Health, Boston, MA, USA. Special thanks belong to Paulina Pino, Department of Epidemiology of Medicine Faculty of Chile University. None of the funding bodies had any role in the study design; in the collection, analysis, and interpretation of data; 
in the writing of the manuscript; or in the decision to submit the manuscript for publication.

\section{Author details}

'Laboratoire de Géosciences Environnement Toulouse (GET), Observatoire Midi-Pyrénées, 14, Avenue Edouard, Belin, Toulouse 31400, France. ${ }^{2}$ Departamento de Geología Aplicada, Servicio Nacional de Geología y Minería de Chile, Avenida Santa María 0104, Providencia 7520405, Santiago, Chile. ${ }^{3}$ Exposure, Epidemiology and Risk Program, Department of Environmental Health, Harvard School of Public Health, Boston, MA, USA. ${ }^{4}$ Centro de Medio Ambiente, Escuela de Ingeniería, Pontificia Universidad Católica de Chile, Vicuña Mackenna 4860, Santiago, Chile. ${ }^{5}$ Finnish Institute of Occupational Health, Kuopio, Neulaniementie, Finland. ${ }^{6}$ Departamento de Geología y Centro de Excelencia en Geotermia de Los Andes (CEGA), Facultad de Ciencias Físicas y Matemáticas, Universidad de Chile, Plaza Ercilla 803, Santiago 8370450, Chile.

Received: 4 June 2012 Accepted: 22 October 2012

Published: 1 November 2012

\section{References}

1. Dominici F, McDermott A, Daniels M, Zeger SL, Samet JM: Revised analyses of the national morbidity, mortality, and Air pollution study: mortality among residents of 90 cities. J Toxicol Environ Health A 2005, 68:1071-1092.

2. Pope CA 3rd, Dockery DW: Health effects of fine particulate air pollution: lines that connect. J Air Waste Manag Assoc 2006, 56:709-742.

3. Katsouyanni K, Zmirou D, Spix C, Sunyer J, Schouten JP, Ponka A, Anderson HR, Le Moullec Y, Wojtyniak B, Vigotti MA, Bacharova L, Schwartz J: Shortterm effects of air pollution on health: a European approach using epidemiologic time series data. The APHEA Project. Air Pollution Health Effects-A European Approach. Public Health Rev 1997, 25:7-18. discussion $19-28$

4. Cifuentes LA, Vega J, Kopfer K, Lave LB: Effect of the fine fraction of particulate matter versus the coarse mass and other pollutants on daily mortality in Santiago, Chile. J Air Waste Manag Assoc 2000, 50:1287-1298.

5. Schwartz J, Dockery DW, Neas LM: Is daily mortality associated specifically with fine particles? J Air Waste Manag Assoc 1996, 46:927-939.

6. Bell ML, Ebisu K, Peng RD, Walker J, Samet JM, Zeger SL, Dominici F: Seasonal and regional short-term effects of fine particles on hospital admissions in 202 US counties, 1999-2005. Am J Epidemiol 2008, 168:1301-1310.

7. Analitis A, Katsouyanni K, Dimakopoulou K, Samoli E, Nikoloulopoulos AK, Petasakis Y, Touloumi G, Schwartz J, Anderson HR, Cambra K, Forastiere F, Zmirou D, Vonk JM, Clancy L, Kriz B, Bobvos J, Pekkanen J: Short-term effects of ambient particles on cardiovascular and respiratory mortality. Epidemiology 2006, 17:230-233.

8. Franklin M, Zeka A, Schwartz V: Association between PM2.5 and all-cause and specific-cause mortality in 27 US communities. J Expo Anal Env Epid 2007, 17:279-287.9.

9. Franklin $\mathrm{M}$, Koutrakis $\mathrm{P}, \mathrm{Sch}$ wartz $\mathrm{P}$ : The role of particle composition on the association between PM2.5 and mortality. Epidemiology 2008, 19:680-689.

10. Bell ML, Ebisu K, Peng RD, Samet JM, Dominici F: Hospital admissions and chemical composition of fine particle air pollution. Am J Respir Crit Care Med 2009, 179:115-1120

11. Zanobetti A, Franklin M, Koutrakis P, Schwartz J: Fine particulate air pollution and its components in association with cause-specific emergency admissions. Environ Health 2009, 8:58.

12. Dominici F, Peng RD, Ebisu K, Zeger SL, Samet JM, Bell ML: Does the effect of PM10 on mortality depend on PM nickel and vanadium content? A reanalysis of the NMMAPS data. Environ Health Perspect 2007 115:1701-1703.

13. Laden F, Neas LM, Dockery DW, Schwartz J: Association of fine particulate matter from different sources with daily mortality in six U.S. cities. Environ Health Perspect 2000, 108:941-947

14. Peng RD, Bell ML, Geyh AS, McDermott A, Zeger SL, Samet JM, Dominici F: Emergency admissions for cardiovascular and respiratory diseases and the chemical composition of fine particle air pollution. Environ Health Perspect 2009, 117:957-963.
15. Romero H, Ihl M, Rivera M, Zalazar P, Azocar P: Rapid urban growth, land-use changes and airpollution in Santiago, Chile. Atmospheric Environment 1999, 33:4039-4047.

16. U.S.EPA: Air quality Criteria for Ozone and Related Photochemical Oxidants (Final Report). Washington, DC: U.S Environmental Protection Agency; 2006.

17. WHO: Air Quality Guidelines, Global Update 2005, Particulate matter, Ozone, Nitrogen Dioxide and Sulfur Dioxide. Rheinbach: Druckpartner Moser; 2005:275-280.

18. Cakmak S, Dales RE, Vida CB: Components of particulate air pollution and mortality in Chile. Int J Occup Environ Health 2009, 15:152-158.

19. Cakmak S, Dales RE, Vidal CB: Air pollution and mortality in Chile: susceptibility among the elderly. Environ Health Perspect 2007, 115:524-527.

20. Habaca M, Olaeta I, Campos E, Villaire J, Tellez-Rojo MM, Romieu I: Association between levels of fine particulate and emergency visits for pneumonia and other respiratory illnesses among children in Santiago, Chile. J Air Waste Manag Assoc 1999, 49:154-163.

21. Dales RE, Cakmak S, Vidal CB: Air pollution and hospitalization for venous thromboembolic disease in Chile. J Thromb Haemost 2010, 8:669-674.

22. Cakmak S, Dales RE, Gultekin T, Vidal CB, Farnendaz M, Rubio MA, Oyola P: Components of particulate air pollution and emergency department visits in Chile. Arch Environ Occup Health 2009, 64:148-155.

23. Sax SN, Koutrakis P, Rudolph PA, Cereceda-Balic F, Gramsch E, Oyola P: Trends in the elemental composition of fine particulate matter in Santiago, Chile, from 1998 to 2003. J Air Waste Manag Assoc 2007, 57:845-855.

24. Berrios V, Acosta E: Red de Monitoreo de Calidad del Aire de la Región Metropolitana: Conformación y principales funciones de los integrantes del equipo de trabajo. Santiago, Chile: Ministerio de Salud, Gobierno de Chile Subsecretaría de Salud Pública del Ministerio de Salud; 2006.

25. Ostro B, Feng WY, Broadwin R, Green S, Lipsett M: The effects of components of fine particulate air pollution on mortality in california: results from CALFINE. Environ Health Perspect 2007, 115:13-19.

26. Pope CA 3rd: Epidemiology of fine particulate air pollution and human health: biologic mechanisms and who's at risk? Environ Health Perspect 2000, 108(Suppl 4):713-723.

27. SAS, Institute, Inc: SAS: SAS Software Release 9.1. Cary, NC: SAS Publishing 2006.

28. R Development Core Team: A Language and Environment for Statistical Computing, version 2.7.2:; 2008.

29. Gallardo L, Olivares G, Langner J, Aarhus B: Coastal lows and sulfur air pollution in Central Chile. Atmospheric Environment 2002 36:3829-3841

30. Zanobetti A, Schwartz J: The effect of fine and coarse particulate air pollution on mortality: a national analysis. Environ Health Perspect 2009, 117:898-903.

31. Ostro B, Sanchez JM, Aranda C, Eskeland GS: Air pollution and mortality: results from a study of Santiago, Chile. J Expo Anal Environ Epidemiol 1996, 6:97-114.

32. Ostro BD, Feng WY, Broadwin R, Malig BJ, Green RS, Lipsett MJ: The impact of components of fine particulate matter on cardiovascular mortality in susceptible subpopulations. Occup Environ Med 2008, 65:750-756.

33. Burnett RT, Brook J, Dann T, Delocla C, Philips O, Cakmak S, Vincent R, Goldberg MS, Krewski D: Association between particulate- and gas-phase components of urban air pollution and daily mortality in eight Canadian cities. Inhal Toxicol 2000, 12(Suppl 4):15-39.

34. Voutsa D, Samara C: Labile and bioaccessible fractions of heavy metals in the airborne particulate matter from urban and industrial areas. Atmospheric Environment 2002, 36:3583-3590.

35. Hedberg E, Gidhagen L, Johansson C: Source contributions to PM10 and arsenic concentrations in Central Chile using positive matrix factorization. Atmospheric Environment 2005, 39:549-561.

36. Artaxo P, Oyola P, Martinez R: Aerosol composition and source apportionment in Santiago de Chile. Nucl Instrum Meth A 1999 150:409-416.

37. Kavouras IG, Koutrakis P, Cereceda-Balic F, Oyola P: Source apportionment of PM10 and PM2.5 in five Chilean cities using factor analysis. J Air Waste Manag Assoc 2001, 51:451-464.

38. Morata D, Polve M, Valdes A, Belmar M, Dinator M, Silva M, Leiva M, Aigouy T, Morales J: Characterisation of aerosol from Santiago, Chile: an integrated PIXE-SEM-EDX study. Environ Geol 2008, 56:81-95. 
39. Zeger SL, Thomas D, Dominici F, Samet JM, Schwartz J, Dockery D, Cohen A: Exposure measurement error in time-series studies of air pollution: concepts and consequences. Environ Health Perspect 2000, 108:419-426.

40. Bland JM, Altman DG: Multiple significance tests: the Bonferroni method. BMJ 1995, 310:170

doi:10.1186/1476-069X-11-82

Cite this article as: Valdés et al:: Elemental concentrations of ambient particles and cause specific mortality in Santiago, Chile: a time series study. Environmental Health 2012 11:82.

\section{Submit your next manuscript to BioMed Central and take full advantage of:}

- Convenient online submission

- Thorough peer review

- No space constraints or color figure charges

- Immediate publication on acceptance

- Inclusion in PubMed, CAS, Scopus and Google Scholar

- Research which is freely available for redistribution 